\title{
STRATEGI PERBAIKAN PROGRAM TABLET TAMBAH DARAH DI KABUPATEN TASIKMALAYA
}

\author{
Baiq Fitria Rahmiati \\ Program Studi Gizi, Universitas Bumigora, Baiqfitriarahmiati@gmail.com
}

INFO ARTIKEL
Riwayat Artikel:
Diterima: 09-02-2019
Disetujui: 20-07-2019

\section{Kata Kunci:}

AHP

Anemia

Ibu Hamil

Suplementasi

Zat Besi

\begin{abstract}
ABSTRAK
Abstrak: Angka Kematian Ibu (AKI) di Indonesia masih tinggi karena rendahnya kepatuhan suplementasi zat besi pada ibu hamil. Hal ini menyebabkan peningkatkan prevalensi anemia pada ibu hamil. Tingginya prevalensi anemia dapat dipengaruhi oleh implementasi program suplementasi zat besi. Penelitian ini bertujuan untuk menganalisis faktor-faktor internal dan eksternal, untuk menemukan strategi alternatif dan strategi prioritas untuk mengoptimalkan program suplementasi besi di Kabupaten Tasikmalaya. Penelitian ini menggunakan studi cross sectional, dengan metode wawancara mendalam kepada para pemangku kepentingan IFA di Kabupaten Tasikmalaya. Data primer dikumpulkan dengan metode wawancara mendalam dengan para ahli. Data sekunder dikumpulkan melalui laporan publikasi dari institusi terkait. Analisis deskriptif pada data primer dan sekunder digunakan untuk menentukan kondisi dan program aplikasi. Analisis Evaluasi Faktor Internal (IFE) dan Evaluasi Faktor Eksternal (EFE) digunakan untuk merumuskan strategi. Pemilihan stretagi alternatif menggunakan metode SWOT, sedangkan prioritas strategis menggunakan AHP. Hasil penelitian menunjukkan bahwa total bobot IFE (2.13) dan EFE (2.12). Analisis SWOT menunjukkan bahwa pemerintah Tasikmalaya perlu meningkatkan komitmen di antara para pemangku kepentingan karena komunikasi yang kurang efektif di antara para pemangku kepentingan. Prioritas strategi adalah peningkatan komitmen, peran dan kemitraan antara para pemangku kepentingan dengan skor total 0483.
\end{abstract}

\begin{abstract}
Maternal Mortality Rate (MMR) in Indonesia is still high due to low compliance of iron supplementation in pregnant women, hence, increasing anemia prevalence among pregnant woman. The unsuccessful program could be influenced by implementation of iron supplementation program. This study aims to analyzed the internal and external factors, to found alternatives strategy and priorities strategy for optimizing Iron Folate suplementation (IFA) program in Tasikmalaya district. The research used cross sectional study, with indepth interviews methode to IFA's stakeholders in Tasikmalaya district. Primary data were collected by indepth interview methode with the experts. The secondary data were collected by publication report of the relevant institution. The descriptive analysis on primary and secondary data is used to determine the condition and application programs. Analysis of Internal Factor Evaluation (IFE) and External Factor Evaluation (EFE) is used to formulate strategies. Selection of alternative stretagi used SWOT methods, while the strategic priorities used AHP. The results showed that total weighted of IFE (2.13) and EFE (2.12). The SWOT analysis indicates that the Tasikmalaya government needs to increase commitment among stakeholders because less effective communication among stakeholders. Strategy priorities is increased commitments, roles and partnerships between stakeholders with a total score 0483.
\end{abstract}

\section{A. LATAR BELAKANG}

Angka Kematian Ibu (AKI) adalah kematian seorang wanita saat hamil atau dalam 42 hari setelah persalinan, yang disebabkan oleh keadaan yang berhubungan dengan kehamilan per 100 ooo kelahiran hidup (WHO 2007). AKI merupakan target global yang ditentukan dalam tujuan pembangunan millenium yaitu meningkatkan kesehatan ibu. Target yang akan dicapai sampai tahun 2015 adalah mengurangi sampai 3/4 resiko jumlah kematian ibu (Kumar et al. 2016) Indonesia berkomitmen untuk menurunkan AKI pada tahun 2015 menjadi 102 per 100.000 kelahiran, namun Indonesia gagal dalam mencapai terget tersebut. AKI di Indonesia masih tetap tinggi yaitu 359 per 100.000 kelahiran hidup (Kemenkes 2015).
Tingginya AKI erat kaitannya dengan terjadinya perdarahan saat melahirkan (Mojekwu et al. 2012; Rush 2000). Penyebab perdarahan berkorelasi kuat dengan anemia pada kehamilan. Beberapa penelitian case-control, longitudinal dan cross-sectional yang dilakukan pada ibu hamil menunjukkan risiko relatif kematian ibu yang dikarenakan anemia dengan ( $\mathrm{OR}=3.5$; 95\% CI:2.0-6.0) (Brabin et al. 2001)

Menurut WHO prevalensi anemia ibu hamil di dunia saat ini $38.2 \%$. Berdasarkan hasil Riset Kesehatan Dasar, prevalensi anemia pada ibu hamil di Indonesia sebesar 37.1\% (Kemenkes 2013). Prevalensi anemia masih tetap tinggi meskipun program suplementasi TTD telah dilaksanakan dalam skala besar (Puspitaningrum et al. 2013). 
Prevalensi anemia pada ibu hamil berhubungan secara signifikan dengan konsumsi Tablet Tambah Darah (TTD) (Lacerte et al. 2011). Konsumsi TTD erat kaitannya dengan pelaksanaan program TTD mencakup input, proses dan output yang akan mempengaruhi kepatuhan dan cakupan serta outcome berupa kejadian anemia (Haddad et al. 2011). Cakupan pemberian TTD di Indonesia pada tahun 2014 sebesar 85.1\%, pemerintah gagal dalam mencapai target cakupan yang ditetapkan pada tahun 2014 yaitu 95\% (Kemenkes 2015). Pemerintah telah melakukan program penanggulangan anemia sejak tahun 1970 dengan memberikan minimal 90 TTD pada ibu hamil, namun kepatuhan ibu hamil untuk mengonsumsi TTD masih rendah yaitu 33.3\% (Kemenkes 2013).

Berdasarkan Laporan Rutin Program Kesehatan Ibu Tahun 2013, Jawa Barat menduduki peringkat tertinggi dalam jumlah AKI di Pulau Jawa. Tasikmalaya merupakan wilayah di Provinsi Jawa Barat dengan tingkat AKI tinggi yaitu 60 per 100.000 kelahiran hidup (7.46\%) tahun 2012 (Kemenkes 2013).

Berdasarkan Briawan et al. (2015) Kepatuhan konsumsi TTD ibu hamil di Kabupaten Tasikmalaya yaitu 33\%, dengan prevalensi anemia lebih tinggi dibandingkan dengan tingkat nasional yaitu 49.06\% dan dikategorikan sebagai masalah kesehatan masyarakat tingkat berat menurut WHO (Dinkes Tasikmalaya 2015; WHO 2007). Peran tenaga kesehatan sebagai penyedia informasi kepada ibu hamil masih kurang. Disisi lain, stakeholder yang menunjang keberhasilan program TTD, masih kurang dalam melakukan koordinasi terkait program TTD. Hal ini dapat menjadi indikasi tingkat keberhasilan program TTD di Kabupaten Tasikmalaya masih rendah.

Tingkat keberhasilan program TTD pada masingmasing wilayah dipengaruhi oleh berbagai faktor. Pengalaman berbagai negara menunjukkan kepatuhan dan cakupan TTD yang rendah karena program suplementasi besi tidak selalu berjalan. Beberapa elemen umum dari kesuksesan program suplementasi besi yang muncul dari pengalaman berbagai negara antara lain dengan memperhatikan faktor-faktor perencanaan pemerintah yang komprehensif terkait kebijakan, sarana prasarana, sumberdaya manusia, anggaran, peran stakeholder, pendistribusian, prosedur kerja, komitmen, serta adanya sistem pengawasan dan pengontrolan (Haddad et al. 2011; Hatta et al. 2014; Kautshar et al. 2013).

Berbagai penelitian tentang sistem pakar dapat membantu menemukan strategi untuk memecahkan berbagai permasalahan. Penelitian yang dilakukan Makkasau tentang penggunaan sistem pakar dalam menentukan prioritas program kesehatan dapat menghasilkan strategi optimalisasi program kesehatan di Kota Ternate (Makkasau 2012).

Penelitian ini bertujuan untuk mempelajari dan menemukan strategi terbaik untuk perbaikan program
TTD melalui persepsi pakar di wilayah Kabupaten Tasikmalaya.

\section{B. METODE PENELITIAN}

Penelitian ini merupakan penelitian kualitatif, menggunakan rancangan cross sectional study. Penelitian dilakukan di Kabupaten Tasikmalaya Provinsi Jawa Barat. Responden penelitian dipilih berdasarkan purposive sampling berjumlah sembilan pejabat daerah pelaksana program suplementasi besi dan tujuh pakar ahli di bidang program TTD. Pengumpulan data dilakukan dengan indepth interview menggunakan pedoman wawancara. Jenis data yang dikumpulkan pada penelitian ini adalah data primer terkait sarana prasarana, mekanisme distribusi TTD, pelaporan penggunaan TTD, kuantitas dan kualitas bidan, upaya sosialisasi dan konseling kepada ibu hamil, program aksi, anggaran, kebijakan serta peran stakeholder internal eksternal dalam pelaksanaan dan aplikasi program di Dinas Kesehatan (Dinkes) Kabupaten Tasikmalaya. Metode analisis untuk mengetahui kondisi dan aplikasi program menggunakan Internal Factor Evaluation (IFE) dan External Factor Evaluation (EFE).

Penentuan rating dengan cara memberi skor 1-4 terhadap seluruh kriteria yang ada. Skor 1 hingga skor 4 berturut-turut memiliki makna sangat tidak penting hingga sangat penting. Penentuan rating masingmasing kriteria didapatkan dari perbandingan dengan kriteria lainnya yang dinilai berdasarkan skala o,1 dan 2 . Skor o memiliki makna bahwa kriteria A lebih tidak penting dibanding kriteria B, skor 1 bermakna kriteria A sama pentingnya dengan kriteria B dan skor 2 memiliki makna bahwa kriteria A lebih penting daripada kriteria B. Bobot IFE dan EFE didapatkan dari perkalian antara skor dan rating. Langkah terakhir adalah merumuskan alternatif strategi menggunakan SWOT. Informasi dikumpulkan oleh peneliti dengan melakukan wawancara indepth interview pada pakar. Wawancara dilakukan sebanyak dua kali, yaitu untuk menentukan faktor internal dan eksternal pada program suplementasi besi yang sedang berjalan, serta untuk menentukan prioritas strategi keberhasilan program suplementasi besi di Kabupaten Tasikmalaya. Wawancara dilakukan selama satu sampai dua jam untuk setiap pertemuan dengan pakar.

\section{HASIL DAN PEMBAHASAN}

\section{Kondisi Faktor Internal}

Berdasarkan hasil wawancara diperoleh beberapa faktor strategis dalam rangka mengoptimalkan program tablet tambah darah di Kabupaten Tasikmalaya. Faktor strategis tersebut terdiri dari faktor internal yang meliputi kekuatan dan kelemahan (Tabel 1). 
TABEL 1

Tabel Internal Factor Evaluation

\begin{tabular}{|c|c|c|c|}
\hline Kekuatan (Strength) & Bobot & $\begin{array}{l}\text { Rat } \\
\text { ing }\end{array}$ & $\begin{array}{c}\text { Sko } \\
\text { r }\end{array}$ \\
\hline $\begin{array}{l}\text { a. } \\
\text { Kerjasama yang baik antar lintas } \\
\text { program Dinas Kesehatan } \\
\text { Kabupaten Tasikmalaya dan } \\
\text { antara petugas kesehatan } \\
\text { diapang untuk program TTD }\end{array}$ & 0.110 & 4 & 0.44 \\
\hline $\begin{array}{l}\text { b. Mekanisme jelas terhadap } \\
\text { perguliran TTD }\end{array}$ & 0.070 & 3 & 0.21 \\
\hline $\begin{array}{l}\text { Terdapat sistem evaluasi } 3 \\
\text { tahunan untuk mengetahui } \\
\text { efektifitas program TTD }\end{array}$ & 0.050 & 2 & 0.10 \\
\hline 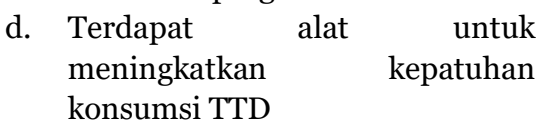 & 0.030 & 3 & 0.09 \\
\hline $\begin{array}{l}\text { e. Kuantitas dan kualitas bidan } \\
\text { telah mencukupi untuk melayani } \\
\text { ibu hamil }\end{array}$ & 0.130 & 2 & 0.26 \\
\hline Kelemahan (Weakness) & & & \\
\hline a. $\quad$ Sarana prasarana tidak memadai & 0.090 & 2 & 0.18 \\
\hline $\begin{array}{l}\text { b. Sistem pencatatan dan pelaporan } \\
\text { penggunaan TTD kurang } \\
\text { maksimal }\end{array}$ & 0.010 & 2 & 0.02 \\
\hline $\begin{array}{l}\text { c. Upaya sosialisasi dan promosi } \\
\text { TTD pada ibu hamil kurang }\end{array}$ & 0.170 & 2 & 0.34 \\
\hline $\begin{array}{l}\text { d. Proses transfer informasi saat } \\
\text { konseling tentang TTD kurang } \\
\text { maksimal }\end{array}$ & 0.150 & 2 & 0.3 \\
\hline $\begin{array}{l}\text { e. Program aksi tentang TTD dan } \\
\text { anemia masih sangat minim }\end{array}$ & 0.190 & 1 & 0.19 \\
\hline Total Skor & 1 & & 2.13 \\
\hline
\end{tabular}

Sumber : Data Primer, 2016

Faktor kekuatan meliputi: 1) Kerjasama yang baik lintas program dalam sektor kesehatan. Penelitian Panduwinata dan Lumintang (2008) disebutkan bahwa hal yang memengaruhi keefektifan suatu program adalah kerjasama antar lintas program. Pada pelaksanaan program suplementasi besi di Kabupaten Tasikmalaya, kerjasama yang dilakukan sudah baik antara seksi gizi, KIA, farmasi, gudang obat dan petugas lapang. 2) Mekanisme yang jelas tentang distribusi suplemen besi di Kabupaten Tasikmalaya. Mekanisme distribusi suplemen besi menjadi salah satu kekuatan program suplementasi besi di Kabupaten Tasikmalaya karena terdapat sistem yang mengatur perpindahan suplemen besi mulai dari perencanaan hingga sampai kepada ibu hamil. 3) Terdapat system evaluasi untuk mengetahui evektifitas program suplementasi besi. Sistem evaluasi yang diadakan oleh Dinas Kesehatan Kabupaten Tasikmalaya adalah melakukan pemeriksaan hemoglobin pada ibu hamil setiap 3 tahun sekali untuk memantau keberhasilan program. 4) Terdapat alat untuk monitor kepatuhan konsumsi suplemen besi (Haddad et al., 2015).

Alat untuk monitor konsumsi suplemen besi di Kabupaten Tasikmalaya adalah kartu kepatuhan ibu yang telah disebarkan mulai tahun 2016. Hal ini menjadi kekuatan program karena dengan adanya kartu kepatuhan, dapat meningatkan ibu untuk mengonsumsi suplemen besi. Menurut penelitian Briawan et al. (2015) salah satu faktor ibu tidak mau mengonsumsi suplemen besi adalah karena lupa sehingga diperlukan alat untuk membantu mengingatkan ibu hamil, salah satunya adalah dengan kartu kepatuhan. 5) Kuantitas dan kualitas bidan telah mencukupi untuk melayani ibu hamil. Kuantitas dan kualitas bidan menjadi hal yang sangat penting karena bidan memiliki peran besar dalam menyampaiakan pesan pada ibu hamil. Penelitian yang dilakukan Priya et al. (2016) menyebutkan bahwa ketersediaan dan pengetahuan tenaga kesehatan dapat memengaruhi keberhasilan program suplementasi besi. Faktor kelemahan meliputi: 1) Sarana prasarana tidak memadai. Sarana prasarana meliputi alat tes hemoglobin dan alat bantu konseling faktor yang memengaruhi keberhasilan program. Kondisi alat tes hemoglobin yang tidak dimiliki oleh seluruh bidan, alat bantu konseling yang kurang lengkap dan kurangnya ketersediaan suplemen besi pada tahun 2016 menjadikan factor tersebut sebagai kelemahan program. 2) Sistem pencatatan dan pelaporan penggunaan suplemen besi kurang maksimal. Dinas Kesehatan Kabupaten

Tasikmalaya telah membuat SOP tentang pengumpulan laporan penggunaan suplemen besi yang dilaksanakan perbulan. Setiap puskesmas wajib mengirimkan laporan tersebut maksimal tanggal 10 setiap bulan. Akan tetapi, hanya 25\% puskesmas yang patuh tentang mengikuti SOP tersebut. 3) Upaya sosialisasi program suplementasi besi pada ibu hamil kurang. Sosialisasi dapat dimanfaatkan pada kelas ibu hamil. Karena keterbatasan dana yang dianggarkan dari BOK maka kelas ibu hamil tidak mampu menjangkau seluruh ibu hamil. 4) Upaya pembinaan tenaga kesehatan kurang maksimal. Upaya pembinaan tenaga kesehatan hanya terbatas pada pertemuan tiga bulan sekali yang diadakan dinkes dengan mengundang 40 bidan perwakilan seluruh puskesmas di Kabupaten Tasikmalaya. 5) Program aksi tentang suplementasi besi dan anemia masih sangat minim. Program aksi merupakan kegiatan mempromosikan manfaat suplemen besi untuk ibu hamil. Anggaran yang tidak mendukung membuat program aksi untuk mempromosikan suplementasi besi tidak dapat dilaksanakan secara maksimal.

Faktor kekuatan yang memiliki skor tertinggi adalah kerjasama yang baik antar lintas program Dinas Kesehatan Kabupaten Tasikmalaya dan petugas kesehatan dilapang untuk pelaksanaan program TTD $(0,44)$. Pada pelaksanaan program TTD di Kabupaten Tasikmalaya, kerjasama antar seksi gizi, KIA/KB, farmasi, gudang obat dan petugas lapang sudah baik. Faktor kunci keberhasilan program tablet tambah darah 
salah satunya yaitu kerjasama yang baik secara internal (Haddad et al. 2011).

Faktor kelemahan yang memiliki skor tertinggi adalah kurangnya upaya sosialisasi dan promosi TTD pada ibu hamil. Hal ini terjadi karena keterbatasan dana yang dianggarkan sehingga upaya sosialisasi tidak mampu menjangkau seluruh ibu hamil. Sosialisasi yang baik merupakan bagian yang sangat menentukan ibu hamil mau atau tidak mengonsumsi TTD (Dureja et al. 2016; Priya et al. 2016). Total skor yang dihasilkan dari Internal Factor Evaluation adalah 2,13 $(<2,5)$, mengindikasikan bahwa program TTD lemah secara internal, belum memanfaatkan kekuatan yang dimiliki secara maksimal dan tidak mengurangi kelemahan yang terdapat dalam internal program (Rangkuti 2015).

\section{Kondisi Faktor Eksternal}

Berdasarkan hasil wawancara diperoleh beberapa faktor strategis dalam rangka mengoptimalkan program tablet tambah darah di Kabupaten Tasikmalaya. Faktor strategis tersebut terdiri dari faktor eksternal yang meliputi peluang dan ancaman (Tabel 2).

TABEL 2

Tabel External Factor Evaluation

\begin{tabular}{|c|c|c|c|}
\hline Peluang (Opportunity) & Bobot & Rating & Skor \\
\hline $\begin{array}{l}\text { a. Permenkes tentang } \\
\text { seruan mengonsumsi } \\
\text { TTD bagi ibu hamil }\end{array}$ & 0.122 & 3 & 0.366 \\
\hline $\begin{array}{l}\text { b. Anggaran pendukung } \\
\text { penyediaan TTD }\end{array}$ & 0.143 & 2 & 0.286 \\
\hline 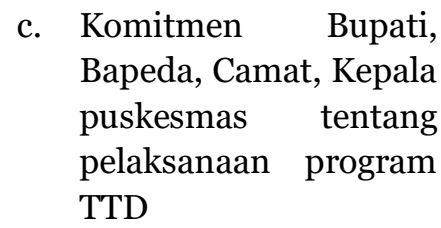 & 0.265 & 3 & 0.795 \\
\hline 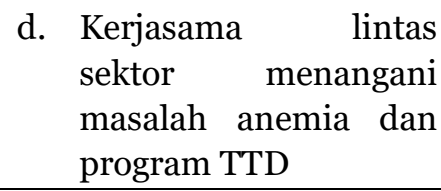 & 0.224 & 1 & 0.224 \\
\hline Ancaman (Threats) & & & \\
\hline $\begin{array}{l}\text { a. Manajemen waktu } \\
\text { pemesanan TTD tidak } \\
\text { terencana dengan baik }\end{array}$ & 0.042 & 1 & 0.042 \\
\hline $\begin{array}{ll}\text { b. Komunikasi yang } \\
\text { kurang lancar antar } \\
\text { stakeholder }\end{array}$ & 0.122 & 2 & 0.244 \\
\hline $\begin{array}{l}\text { c. Komitmen kurang dari } \\
\text { rekanan untuk } \\
\text { menyediakan TTD }\end{array}$ & 0.082 & 2 & 0.164 \\
\hline Total Skor & 1 & & 2.121 \\
\hline
\end{tabular}

Sumber : Data Primer, 2016

Evaluasi faktor eksternal didapatkan dari beberapa peluang dan ancaman faktor yang memengaruhi program suplementasi besi, dinilai berdasarkan persoalan ekonomi, sosial, demografi, lingkungan, pemerintahan dan teknologi oleh para pemangku kepetingan (Rangkuti 2015). Peluang yang diperoleh yaitu: 1) terdapat Permenkes No 97 Tahun 2014 tentang suplementasi besi pada ibu hamil menyatakan bahwa setiap ibu hamil wajib diberikan minimal 90 tablet besi selama masa kehamilan hingga masa nifas; 2) anggaran pendukung dari dana desa dapat digunakan untuk meningkatkan derajat kesehatan masyarakat; 3) terdapat komitmen Bupati dan Bappeda, tentang pelaksanaan program suplementasi besi. Komitmen menjadi dasar keberhasilan suatu program sesuai yang disampaikan dalam Guideline Iron Suplementation oleh Stoltzfus dan Dreyfuss (2011).

Ancaman yang diperoleh yaitu: 1) manajemen waktu pemesanan suplemen besi tidak terencana dengan baik. Kekosongan suplemen besi salah satunya disebabkan oleh manajemen waktu yang ditetapkan oleh pusat. Berdasarkan aturan yang telah dibuat, proses pemesanan dilakukan bulan Oktober sebelum tahun anggaran berjalan dan jika terjadi kekurangan stok dapat memesan lagi pada trimester tiga yaitu bulan Juli pada tahun anggaran yang sedang berjalan.

Hal ini menjadikan di Kabupaten Tasikmalaya terjadi kekosongan stok suplemen; 2) komitmen kurang dari rekanan untuk menyediakan suplemen besi. Kementerian Kesehatan menerbitkan spesifikasi suplemen besi baru yaitu kandungan setara dengan 60 mg besi elemental dan $0.4 \mathrm{mg}$ asam folat. Suplemen besi spesifikasi baru yang dikirim oleh rekanan bermerk Lexavit isi 10 dalam kemasan blister. Namun rekanan tidak mampu memenuhi seluruh pesanan Kabupaten Tasikmalaya; 3) komunikasi yang kurang lancar antar stakeholder. Komunikasi antar stakeholder merupakan kunci kesuksesan program suplementasi besi. Karena masalah gizi bukan hanya tanggung jawab Dinas Kesehatan, namun merupakan tanggung jawab stakeholder di luar kesehatan. Berdasarkan wawancara yang dilakukan pada seluruh pemangku kepentingan, didapatkan data bahwa terjadi komunikasi yang belum efektif antar lintas stakeholder.

Faktor peluang yang memiliki skor tertinggi adalah terdapat komitmen Bupati, Bapeda, Camat, Kepala puskesmas tentang pelaksanaan program TTD. Hal ini karena stakeholder tersebut telah mengetahui dan menyepakati secara bersama bahwa program TTD kaitannya dengan anemia menjadi salah satu faktor AKI di Kabupaten Tasikmalaya. AKI digunakan sebagai indikator keberhasilan daerah. Oleh karena itu, terdapat kesepakatan bahwa penyebab AKI harus diatasi. Komitmen menjadi dasar keberhasilan suatu program sesuai yang disampaikan dalam guideline iron suplementation (Haddad et al. 2011).

Faktor ancaman yang memiliki skor tertinggi adalah komunikasi yang kurang baik antar stakeholder, ditandai dengan beberapa stakeholder terkait masih menganggap permasalahan kesehatan yang kaitannya 
dengan program TTD merupakan tanggung jawab Dinas Kesehatan saja. Hal ini ditandai dengan stakeholder di luar Dinas Kesehatan tidak mengetahui informasi, kebutuhan, serta apa yang mereka harus lakukan untuk membantu mengoptimalkan program.

Total skor yang dihasilkan dari External Factor Evaluation adalah 2,121. Total skor 2,121 kurang dari nilai rata-rata yang ditetapkan yaitu 2,5. Total skor tersebut mengindikasikan bahwa secara eksternal, pelaksanaan program TTD belum merespon dengan sangat baik terhadap peluang dan tidak menghindari ancaman eksternal yang ada. Program TTD di Kabupaten Tasikmalaya belum secara efektif mengambil keuntungan dan belum menghindari ancaman eksternal yang muncul (Rangkuti 2015).

\section{Alternatif Strategi Perbaikan Program TTD}

Alternatif strategi dihasilkan melalui tahap pencocokan pada faktor internal dan eksternal (Tabel 3). Analisis didasarkan pada logika yang dapat memaksimalkan kekuatan (Strengths) dan peluang (Opportunities), namun secara bersamaan dapat meminimalkan kelemahan (Weaknesses) dan ancaman (Threats) (Rangkuti 2015).

TABEL 3

Tabel Strength, Weakness, Opportunity, Threats

\begin{tabular}{lll}
\hline & \multicolumn{1}{c}{ Kekuatan (S) } & Kelemahan (W) \\
\hline Peluang (O) & $\begin{array}{l}\text { Peningkatan } \\
\text { komitmen, peran } \\
\text { dan kemitraan } \\
\text { antar stakeholder. }\end{array}$ & $\begin{array}{l}\text { Peningkatan sarana } \\
\text { prasarana pendukung } \\
\text { program TTD }\end{array}$ \\
\hline Ancaman & Peningkatan & Peningkatan program \\
(T) & kapasitas tenaga & aksi untuk \\
& kesehatan & mensosialisasikan \\
& & informasi pentingnya \\
& & TTD \\
\hline
\end{tabular}

Strategi peningkatan komitmen, peran dan kemitraan antar stakeholder perlu dikembangkan karena masalah gizi merupakan tanggung jawab lintas sektoral yang penanganannya harus melibatkan lintas sekor. Strategi peningkatan sarana prasarana pendukung TTD perlu dikembangkan karena faktor yang mempengaruhi terlaksananya program TTD dengan baik adalah adanya sarana prasarana mendukung seperti alat test hemoglobin, media konseling, ketersediaan TTD, upaya sosialisasi TTD kepada ibu hamil, dapat mengoptimalisasi program. Peningkatan kapasitas tenaga kesehatan perlu dikembangkan karena tenaga kesehatan memiliki peran strategis agar ibu hamil patuh dalam mengonsumsi TTD. Peningkatan kapasitas tenaga kesehatan dapat berupa pemberian workshop, pelatihan atau seminar tentang manajemen waktu dan cara konseling yang efektif agar ibu hamil patuh mengonsumsi TTD. Peningkatan program aksi dapat dikembangkan dengan mengaksikan kegiatan kegiatan yang dapat meningkatkan kepedulian ibu hamil mengonsumsi TTD.

\section{Prioritas Strategi Perbaikan Program TTD}

Penyusunan prioritas strategi bergantung pada imajinasi, pengalaman, dan pengetahuan untuk menyusun hierarki suatu masalah pada logika, intuisi dan pengalaman untuk memberikan pertimbangan. Prioritas strategi yang dihasilkan menunjukan bahwa Kabupaten Tasikmalaya perlu meningkatkan komitmen, peran dan kemitraan antar stakeholder untuk mengoptimalkan program tablet tambah darah dengan jumlah bobot 0.483 (Gambar 1). Prioritas strategi ini dapat dijalankan dengan memaksimalkan peran dan komunikasi antar stakeholder. Hal ini sesuai yang disampaikan oleh Dureja et al bahwa peranan berbagai stakeholder mampu menga mampu meningkatkan kepatuhan konsumsi TTD (Dureja et al. 2016).

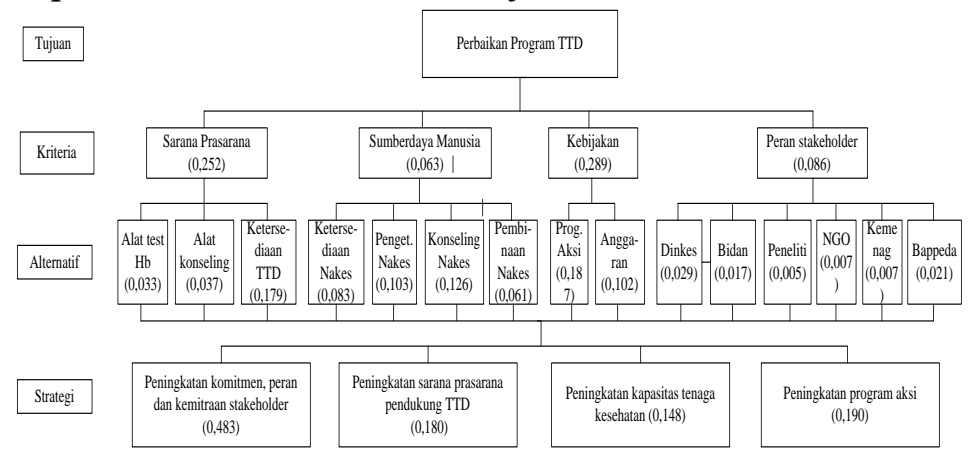

Gambar 1. Bobot Prioritas Strategi Perbaikan Program Tablet Tambah Darah

Peningkatan komitmen, peran dan kemitraan stakeholder dapat dilakukan dengan adanya kesadaran bersama bahwa program tablet tambah darah merupakan program yang penting bagi ibu hamil untuk mengatasi anemia atau mencegah ibu hamil menjadi anemia (Mutmainah 2014). Peningkatan komitmen, peran dan kemitraan stakeholder berupa kesepakatan bersama mengenai pentingnya menangani ibu hamil anemia melalui program pemberian TTD oleh stakeholder terkait yaitu Dinas Kesehatan Kabupaten Tasikmalaya, Bapeda, Kemenag, Perguruan tinggi/peneliti dan NGO (Hatta et al. 2014). Implementasi dibuktikan berupa berita acara ketika terjadi pertemuan untuk menyepakati komitmen, menyadari peran penting stakeholder terkait, dan bentuk kemitraan yang akan dijalin oleh stakeholder yang memiliki peran penting untuk mengoptimalkan tablet tambah darah. Peningkatan peran stakeholder adalah seluruh stakeholder berperan sesuai tugasnya masing-masing dengan maksimal, sebagai contoh peneliti dan perguruan tinggi berperan dengan baik untuk meneliti dan memberikan saran strategi untuk mengoptimalkan program tablet tambah darah agar prevalensi anemia ibu hamil dapat turun di Kabupaten Tasikmalaya. 
Peningkatan kemitraan stakeholder adalah peningkatan kerjasama antar stakeholder yang berperan pada program tablet tambah darah, sebagai contoh kerjasama antar Dinas Kesehatan dan Kemenag agar calon pengantin harus diberikan edukasi gizi dan pemeriksaan status anemia sebagai salah satu syarat pernikahan (Kautshar et al. 2013). Beberapa stakeholder yang berperan dalam program TTD antara lain Bapeda, Kemenag, Puskesmas, Peneliti, Perguruan Tinggi, Non Goverment Organization, Ikatan Bidan Indonesia, Litbang serta Dinas Kesehatan dan bidan. Sesuai dengan Undang-Undang Nomor 18 Tahun 2002 tentang Sistem Nasional Penelitian, Pengembangan, dan Penerapan Ilmu Pengetahuan Dan Teknologi, menyatakan bahwa pemerintah wajib melakukan penelitian dan pengembangan ilmu pengetahuan dan teknologi secara terus-menerus, dan mendorong serta menyinergikan kegiatan penelitian dan pengembangan program yang dilakukan oleh pemerintah daerah, lembaga pendidikan, lembaga penelitian, pelaku usaha dan masyarakat guna keberlanjutan (Kemendikbud 2002).

\section{SIMPULAN DAN SARAN}

Hasil penilaian pada matriks IFE menunjukkan bahwa program TTD memiliki posisi internal yang belum cukup kuat dengan nilai 2,12. Matriks EFE dengan nilai 2,13 menunjukkan bahwa pelaksana program tablet tambah darah belum dapat merespon lingkungan eksternal dengan efektif. Berdasarkan analisis SWOT, maka alternatif strategi yang dapat diterapkan untuk meningkatkan program TTD di Kabupaten Tasikmalaya antara lain peningkatan komitmen, peran dan kemitraan stakeholder, peningkatan sarana prasarana pendukung program TTD, peningkatan kapasitas tenaga kesehatan, dan peningkatan program aksi untuk mempromosikan TTD di Kabupaten Tasikmalaya. Prioritas strategi yang perlu diambil dalam upaya perbaikan program TTD di Kabupaten Tasikmalaya adalah meningkatkan komitmen, peran dan kemitraan stakeholder dengan skor 0,483 .

Dibutuhkan penelitian lanjutan dengan wilayah penelitian yang lebih luas untuk mengkomparasi hasil. Pemerintah daerah Kabupaten Tasikmalaya perlu meningkatkan aspek komitmen, peran dan kemitraan antar stakeholder agar program TTD dapat berjalan maksimal sehingga dapat menurunkan prevalensi anemia di Kabupaten Tasikmalaya.

\section{UCAPAN TERIMA KASIH}

Penulis mengucapkan terimakasih yang sebesarbesarnya kepada Kepala Dinas Kesehata Kabupaten Tasikmalaya yang telah membantu dan mengizinkan penulis untuk melakukan penelitian di Kabupaten Tasikmalaya.

\section{DAFTAR RUJUKAN}

[1] Brabin BJ, Hakimi M, Pelletier D. 2001. An analysis of anemia and pregnany-related maternal mortality. Journal Nutrition. 131(52):604-607.

[2] Briawan, D, Madanijah, S, Furqon, LA, Dainy, NC. 2015. Efektifitas Intervensi Peningkatan Kapasitas Tenaga Kesehatan Tentang Suplementasi Gizi pada Ibu Hamil dalam Upaya Menurunkan Angka Kematian Ibu [Laporan PUPT]. Bogor (ID): Institut Pertanian Bogor.

[3] [Dinkes] Dinas Kesehatan Kabupaten Tasikmalaya. 2015 Profil kesehatan Kabupaten Tasikmalaya 2014 [Laporan tahunan]. Tasikmalaya (ID): Dinas Kesehatan Kabupaten Tasikmalaya.

[4] Dureja S. 2016. Weekly Iron and Folic Supplementation Program in India [Report]. India: Ministry of Health \& Family Welfare Goverment of India.

[5] Hatta H, Dachlan DM, Salam A. 2014. Studi pelaksanaan program suplementasi tablet besi (Fe) untuk ibu hamil di Puskesmas Maradekaya Kota Makassar. Jurnal Sains Kesehatan. 54(3):1-14.

[6] Haddad L, Howkes C, Udomkesmalle E, Achadi E, Bendech MA, Ahuja A, Bhutta Z, Regil RD, Facassi P, Strawn LMG et al. 2011. Global Nutrition Report. From Promise to Impact Ending Malnutrition by 2030 [Report]. Washington DC: International Food Policy Research Institute.

[7] Kautshar N, Suriah, Jafar N. 2013. Kepatuhan ibu hamil dalam mengkonsumsi tablet zat besi (Fe) di Puskesmas Bara-Baraya Tahun 2013. Media Kesehatan Masyarakat Indonesia. 1(3):1-15.

[8] [Kemendikbud] Kementerian Pendidikan dan Kebudayaan. 2002. Undang-Undang No 18 Tahun 2002. Tentang Sistem Nasional Penelitian, Pengembangan, dan Penerapan Ilmu Pengetahuan Dan Teknologi. Jakarta (ID): Kementerian Pendidikan dan Kebudayaan RI.

[9] [Kemenkes] Kementerian Kesehatan RI. 2015. Pedoman penatalaksanaan pemberian tablet tambah darah. Jakarta (ID): Kementerian Kesehatan RI.

[10] [Kemenkes] Kementerian Kesehatan RI. 2013. Hasil riset kesehatan dasar 2013. Jakarta (ID): Badan Penelitian dan Pengembangan Kesehatan.

[11] Kumar S, Kumar N, Vivekadhish S. 2016. Millennium Development Goals (MDGs) to Sustainable Development Goals (SDGs): addressing unfinished agenda and strengthening sustainable development and partnership. Indian J Community Med. 41(1):1-4.doi: 10.4103/09700218.170955.

[12] Lacerte, Pradipasen $M$, Temcharoen P, Imamee N, Vorapongsathorn T. 2011. Determinants of adherence to iron/folate supplementation during pregnancy in two provinces in Cambodia. Asia-Pacific Journal Of Public Health. 23(2):315-323.

[13] Makkasau K. 2012. Penggunaan metode Analytic Hierarchy Process (AHP) dalam penentuan prioritas program kesehatan (studi kasus program promosi kesehatan). Jurnal Manajemen Kesehatan Indonesia. 7(2):105-113.

[14] Mojekwu, Namdi J, Ibekwe, Uche. 2012. Maternal mortality in Nigeria: examination of intervention methods. International Journal of Humanities and Social Science. 2(2):20-25.

[15] Mutmainah VT, Nugraheni SA, Suparwati A. 2014. Analisis perbedaan implementasi program suplementasi tablet besi ibu hamil oleh petugas gizi antara puskesmas cakupan tinggi dan rendah di Wilayah Kabupaten Kendal. Jurnal Manajemen Kesehatan Indonesia. 2(2):1-10.

[16] Priya S, Datta SS, Baharupi BS, Narayan KA, Ambarasan N, Ramya RN. 2016. Factors influencing weekly IFA supplementation program: where to focus our attention? International Journal of Contemporary Medical Research. 3(4):1-7. 
[17] Puspitaningrum D, Damayanti FN, Mustika DN. 2013 Efektivitas pemberian tablet $\mathrm{Fe}$ dalam meningkatkan kadar haemoglobin pada ibu hamil trimester II dan trimester III dengan anemia di Puskesmas Bangetayu Kecamatan Genuk tahun 2013. Media Gizi Pangan. 8(1):7-11.

[18] Rangkuti F. 2015. Teknik Membedah Kasus Bisnis Analisis SWOT. Jakarta (ID): Gramedia Pustaka Utama.

[19] Rush D. 200o. Nutrition and maternal mortality in the developing world. Am J Clin Nutr. 72(suppl):21-40.

[20] [WHO] World Health Organization. 2007. Worldwide prevalence of anemia 1993-2005: WHO Global Database on Anemia [Report]. Geneva World Health.

\section{PROFIL PENULIS UTAMA}

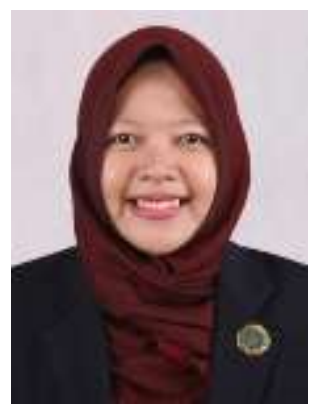

Penulis dilahirkan di Kota Mataram, Provinsi Nusa Tenggara Barat pada tanggal 7 April 1992 sebagai anak ketiga dari empat bersaudara dari pasangan Bapak $\mathrm{H}$ Lalu Wildan SSos dan Ibu Baiq Saleha SPd. Penulis melewati pendidikannya mulai SD sampai SMA di kota Mataram. Pendidikan formal dijalani penulis berawal dari SDN 06 Mataram (1998-2003), SMPN 02 Mataram (2004-2007), dan SMAN 01 Mataram (2007-2010). Tahun 2010 penulis diterima masuk Universitas Brawijaya melalui jalur seleksi SNMPTN pada IImu Gizi Fakultas Kedokteran. Penulis meraih gelar Sarjana Gizi pada tahun 2014 dengan penelitian berjudul "Pengaruh Frekuensi Penggorengan dan Penambahan Sari Mengkudu terhadap Kadar Asam Lemak Trans Minyak Jelantah". Selama pendidikan Sarjana, penulis aktif sebagai Badan Pengawas Inti BEM Fakultas Kedokteran dan Pengurus Harian Nasional pada Ikatan Lembaga Mahasiswa Gizi Indonesia. Setelah lulus pendidikan S1, penulis pernah bekerja sebagai enumerator pada Survey Pemantauan Status Gizi Balita - Kementerian Kesehatan pada tahun 2014 dan enumerator pada Survey Kehidupan Rumah Tangga Indonesia pada tahun 2015. Pada tahun 2015, penulis berkesempatan melanjutkan pendidikan magister (S2) melalui Beasiswa Unggulan Kemendikbud pada Program Studi Ilmu Gizi, Fakultas Ekologi Manusia, Institut Pertanian Bogor. Selama mengikuti program S2, penulis berkesempatan untuk terlibat dalam penelitian unggulan perguruan tinggi (PUPT) -Efektivitas Intervensi Peningkatan Kapasitas Tenaga Kesehatan tentang Suplementasi Gizi pada Ibu Hamil dalam Upaya Menurunkan Angka Kematian Ibu pada tahun 2016 sebagai asisten lapang. Selain itu, penulis juga berkesempatan menjadi Koordinator Lapang pada penelitian yang berjudul -Faktor-faktor yang memengaruhi status hidrasi ibu hamil dan panjang serta berat badan bayi. Penulis juga aktif sebagai Divisi Kependidikan pada Forum Mahasiswa Gizi Indonesia. Penulis telah melakukan publikasi jurnal pada International Journal Science Basic Applied Research (IJSBAR) Tahun 2017 volume 33, No 3, halaman 22-30, dengan judul Internal and External Factor Evaluation of Implementation Iron Supplementation Program for Pregnant Woman in Tasikmalaya District dan publikasi pada jurnal Media Gizi Mikro Indonesia Litbangkes dengan judul Studi Kualitatif tentang Faktor dan Strategi Perbaikan Program Suplementasi Besi Ibu Hamil dengan Kasus di Kabupaten Tasikmalaya. 